\title{
Measuring Teachers' Learning from a Problem-Based Learning Approach to Professional Development in Science Education
}

\author{
Ayelet Weizman \\ Beth A. Covitt \\ Matthew J. Koehler \\ Mary A. Lundeberg \\ Joy A. Oslund
}

See next page for additional authors

IJPBL is Published in Open Access Format through the Generous Support of the Teaching Academy at Purdue University, the School of Education at Indiana University, and the Jeannine Rainbolt College of Education at the University of Oklahoma.

\section{Recommended Citation}

Weizman, A. , Covitt, B. A. , Koehler, M. J. , Lundeberg, M. A. , Oslund, J. A. , Low, M. R. , Eberhardt, J. , \& Urban-Lurain, M. (2008). Measuring Teachers' Learning from a Problem-Based Learning Approach to Professional Development in Science Education. Interdisciplinary Journal of Problem-Based Learning, 2(2).

Available at: https://doi.org/10.7771/1541-5015.1081

This document has been made available through Purdue e-Pubs, a service of the Purdue University Libraries. Please contact epubs@purdue.edu for additional information.

This is an Open Access journal. This means that it uses a funding model that does not charge readers or their institutions for access. Readers may freely read, download, copy, distribute, print, search, or link to the full texts of articles. This journal is covered under the CC BY-NC-ND license. 


\section{Measuring Teachers' Learning from a Problem-Based Learning Approach to Professional Development in Science Education}

\section{Authors}

Ayelet Weizman, Beth A. Covitt, Matthew J. Koehler, Mary A. Lundeberg, Joy A. Oslund, Mark R. Low, Janet Eberhardt, and Mark Urban-Lurain 


\title{
Measuring Teachers' Learning from a Problem-Based Learning Approach to Professional Development in Science Education
}

\author{
Ayelet Weizman, ${ }^{*}$ Beth A. Covitt, ${ }^{*}$ Matthew J. Koehler, Mary A. Lundeberg, \\ Joy A. Oslund, Mark R. Low, Janet Eberhardt, and Mark Urban-Lurain
}

\begin{abstract}
In this study we measured changes in science teachers' conceptual science understanding (content knowledge) and pedagogical content knowledge (PCK) while participating in a problem-based learning (PBL) model of professional development. Teachers participated in a two-week long workshop followed by nine monthly meetings during one academic year that focused on deepening their content understanding and their teaching practices. We analyzed teachers' short writings and concept map depictions of their understanding, and found teachers significantly developed components of pedagogical content knowledge and clinical reasoning, such as knowledge of assessment. Gains on conceptual understanding of science, however, were limited to one group of teachers. We conclude that this PBL approach to professional development advanced components of science teachers' strategic pedagogical content knowledge and discuss the ongoing challenges in measuring changes in teachers' understanding in the context of an evolving PBL model of professional development.
\end{abstract}

Keywords: Problem Based Learning, Professional Development, Concept Maps, PCK, Teacher Learning

\section{Measuring Teachers' Learning from a Problem-Based Learning Approach to Professional Development in Science Education}

Problem-based learning (PBL) is a pedagogical approach that uses real-world problems to develop learners' knowledge and problem-solving skills (Albanese \& Mitchell, 1993; Mayo, Donnelly, Nash, \& Schwartz, 1993). Small groups of learners are presented with an ill-structured problem that does not include all the information needed to solve it (Albanese \& Mitchell, 1993) and that may have more than one solution. With the help of a facilitator, participants cycle through a process of defining what they already know,

* The contributions of the first two authors were equal.

The Interdisciplinary Journal of Problem-based Learning • volume 2, no. 2 (Fall 2008) 
identifying learning issues, hypothesizing proposed solutions, and proceeding to selfstudy. The group reconvenes to synthesize ideas, and finally comes to a decision about the problem using evidence (if possible), or decides to follow up on new learning issues and hypotheses if warranted (Duch, 2001; Levin, 2001).

Much of the research supporting the effectiveness of PBL comes from studies in medical schools (Albanese \& Mitchell, 1993; Barrows \& Tamblyn, 1980; Dochy, Segers, Van den Bossche, \& Gijbels, 2003). In medical education, the PBL process is designed to mirror the clinical reasoning process of doctors, which often involves making complex decisions with incomplete information about patient problems. The PBL approach to medical education has been successful at fostering learners' growth in many areas, including problem solving, critical thinking, conceptual understanding, self-directed learning, and intrinsic motivation for learning (Hmelo-Silver, 2004; Sage, 2001). A major finding is that medical students' clinical reasoning skills have been developed through PBL (Albanese \& Mitchell, 1993; Barrows \& Tamblyn, 1980; Scaffa \& Wooster, 2004). For example, in a recent meta-analysis of studies on PBL in medical schools, Dochy et al. (2003) found that, compared with students in traditional lecture-based courses, students in PBL courses gained slightly less content knowledge but were better able to apply knowledge and higher order thinking skills.

\section{PBL as a Tool for Developing Teacher Knowledge}

Promising results in medical education have inspired educators in other professional fields to adapt PBL to their own contexts. PBL has been used in occupational therapy (Scaffa \& Wooster, 2004), nursing (Newman, 2004; Newman, Ambrose, Corner, Quinn \& Tymms, 2001), undergraduate science courses (Allen, Duch, Groh, Watson, \&White, 2003), preparation of pre-service teachers (Butler, 2003; Derry, Seymour, Fassnacht, \& Feltovich, 2001), undergraduate economics courses (Capon \& Kuhn, 2004), and educational psychology (Chernobilsky, DaCosta, \& Hmelo-Silver, 2004). In our research, we focus on developing and evaluating a model that uses problem-based learning for the professional development of science teachers.

Although the contexts for physicians' and science teachers' decisions are different (e.g., physicians' decisions generally concern individual patients and science teachers deal with groups of students with diverse needs and goals), there are also many similarities. Both groups of professionals must make complicated, reasoned decisions (a process called clinical reasoning) that have several components:

- Strong conceptual understanding. Physicians need a strong understanding of medical knowledge that can be quickly and accurately recalled to make correct diagnoses. Teachers, similarly, need to have a wide and deep understanding of the subject matter they are teaching (National Research Council, 1996). Current 
research, however, suggests that K-8 science teachers have limited science conceptual understanding (Committee on Science Learning, 2007a).

- The ability to apply knowledge. The ability to recall and apply knowledge in new or unanticipated contexts is necessary for problem solving in practice (Reich, 1990).

- The ability to reason with incomplete information. Faced with just a few facts, physicians typically ask questions and order a few tests to get more information. Teachers face a similar task. They must use limited information they have about their students' knowledge, motivations, and individual learning needs to make decisions about what to do next that will be best for the class as well as for individual students.

- Motivation for self-directed learning. Like physicians, who cannot rely on knowledge they acquired in medical school once in practice, teachers must also stay updated on subjects they teach. In addition, teachers need to stay apprised of frequent changes in local and state standards, as well as current thinking about science pedagogy (e.g., National Research Council, 2000).

These components of clinical reasoning fit well with demonstrated outcomes of PBL: increased conceptual understanding, development of problem-solving skills, increased skill with professional decision-making, opportunities to collaborate with peers, enhancement of self-directed learning skills (Chernobilsky et al., 2004; Hmelo-Silver, 2004), and increased intrinsic motivation for learning (Hmelo-Silver, 2004). Given this fit, PBL may be a promising approach for developing the reasoning teachers use in their classrooms.

As clinicians, teachers must assess and adjust their practice to reflect new knowledge, research and experiences. Therefore, they need lifelong, ongoing professional development to support their learning of conceptual understanding and pedagogical content knowledge (PCK) (Darling-Hammond \& Ball, 1998; National Research Council, 1996; National Staff Development Council, 2001). As they investigate teaching practice through PBL, teachers may become more reflective practitioners (Schön, 1983; Van Zee, Lay, \& Roberts, 2003; Zeicher \& Liston, 1996), who share their thoughts through interaction in collaborative communities of learning (Loucks-Horsley, Love, Stiles, Mundry, \& Hewson, 2003; National Research Council, 1996; National Staff Development Council, 2001).

Through ongoing professional development and practice using PBL, we suggest that teachers can develop the ability to apply their knowledge in real classroom settings (i.e., use clinical reasoning) and assess the effectiveness of their actions and revise plans according to the evidence they collect and interpret. To date, however, there has been little research examining the use of PBL for teacher professional development. In a few studies focusing primarily on teachers' use of PBL in their own classrooms, teachers reported changes in their enthusiasm for teaching, critical thinking skills, and classroom 
practices (e.g., Sage, 2001). In contrast, this study focused on measuring the impact of a PBL for Teachers model of professional development on teachers' content and pedagogical content knowledge.

\section{Model of Professional Development in the PBL for Teachers Project}

The PBL for Teachers model of professional development was created as part of an ongoing five-year NSF-funded PBL professional development project using a design-based research approach. Design-based research is research that 1) connects the central goals of designing learning environments and developing theories of learning; 2) carries out development and research through iterative cycles of design, enactment, analysis, and redesign; and 3 ) includes communication of theories and implications to practitioners and other education designers (Cobb, 2001; Collins, 1992; Design-Based Research Collective, 2003). Following this approach, the design and research components of our project are evolving and informing one another throughout the five years of this project. Thus, the findings we share here provide insight not only into the impact of our initial year of professional development, but also into how this work has influenced our continuing cycles of design and research within the project.

The PBL for Teachers Project was intended to help in-service teachers from local K-12 schools examine problems of science content and pedagogy in a self-selected content area (e.g., Life Science). The major components included:

\section{Application Process}

In their application, teachers selected an area of science they found challenging (i.e., Life Science, Earth Science, Physics) and chose a unit to revise to increase student understanding (e.g., genetics). They also specified if they wanted to participate only in one week of professional development focusing on science content, or also participate in an additional week during the summer and meetings throughout the coming school year focusing on pedagogical content knowledge.

\section{Orientation Meeting}

In this three hour meeting, teachers were introduced to PBL and the project goals, and were given an opportunity to work through a practice problem.

\section{Summer Workshop (Week One)}

During week one, the teachers worked on four to seven problems designed to deepen their content knowledge at a conceptual level (see example in Appendix A). They were 
divided into three groups based on their chosen area of science. Participants also began working individually on the units they chose to revise and were guided to focus on big ideas, main misconceptions, inquiry applications, and assessment methods. The topic of assessment, in particular, was highlighted.

\section{Summer Workshop (Week Two)}

During the second week, participants worked on PBL problems that addressed teaching practices. The main topics addressed by the problems were assessment, inquiry, and instructional decision-making (See example in Appendix A). During week two, each teacher developed a teaching problem to study using PBL in the upcoming academic year. For example, one teacher chose to study the problem, "What are effective ways to help students understand how electric circuits work?" Facilitators helped to define and develop problems through discussions and searching for resources.

\section{Academic Year Meetings}

Teachers who chose to continue with the project met for nine monthly meetings in learning community groups throughout the $2005-2006$ school year. They continued to use PBL to study their teaching with the support of other teachers, project facilitators, and researchers. During meetings, teachers shared video or written descriptions of their teaching problems and discussed the issues, hypotheses, and possible courses of action that arose.

\section{End of Year Sharing}

At the end of the academic year, participants shared the results of their PBL work in a poster presentation session. Teachers described the problem they addressed, the hypotheses they formed, the research and resources they located, the data they collected, and any conclusions that they reached. This session also served as one part of the orientation for the next cohort of teachers entering the project.

\section{Defining Teacher Knowledge in the PBL for Teachers Project}

The PBL Project for Teachers is primarily interested in developing two categories of knowledge: 1) conceptual content knowledge, and 2) pedagogical content knowledge. Both forms of knowledge are consistent with the goals of PBL (Hmelo-Silver, 2004) and of science teacher educators (National Research Council, 1996). The concept of content knowledge is straightforward; it may be defined as the amount and organization of subject matter knowledge held in the mind (Shulman, 1986). Pedagogical content knowledge (PCK), by contrast, is more complex in definition.

- volume 2, no. 2 (Fall 2008) 
Shulman (1986) described PCK to include "...the ways of representing and formulating the subject, that make it comprehensible to others" (p. 9). Shulman suggested a conception of teaching where principled skills and well-studied cases are brought together in the form of "strategic pedagogical knowledge"(p.12). Shulman suggested the use of case methods in teacher education "... as a means for developing strategic understanding, for extending capacities toward professional judgment and decision making" (p. 13). Thus, strategic pedagogical content knowledge, according to Shulman, is a way to organize content, pedagogy, and curriculum in a form that can be drawn upon for decision-making in the classroom.

We argue that Shulman's concept of strategic pedagogical content knowledge is the deep, well-organized knowledge about pedagogy and content necessary for clinical reasoning. For teachers, strategic PCK means knowing how to apply PCK components in the classroom in specific situations. This argument is supported by previous studies of the use of problem-based and case-based methods (Hmelo-Silver, 2004; Levin, 1995, 2001; Sage, 2001).

Shulman's framework for pedagogical content knowledge was later developed and redefined (Segall, 2004; Veal \& MaKinster, 1999), expanded to include new components (Barnett \& Hodson, 2001; Magnusson, Krajcik, \& Borko, 1999; Mishra \& Koehler, 2006), and studied to show how it can be developed among teachers (Jones, Rua \& Carter, 1998; van Driel, Verloop, \& de Vos, 1998).

Of particular importance to this study is a model of PCK for science teachers offered by Magnusson et al. (1999), following and extending the work of Anderson and Smith

Figure 1. A model of the relationships between the components of PCK (from Magnusson et al., 1999)

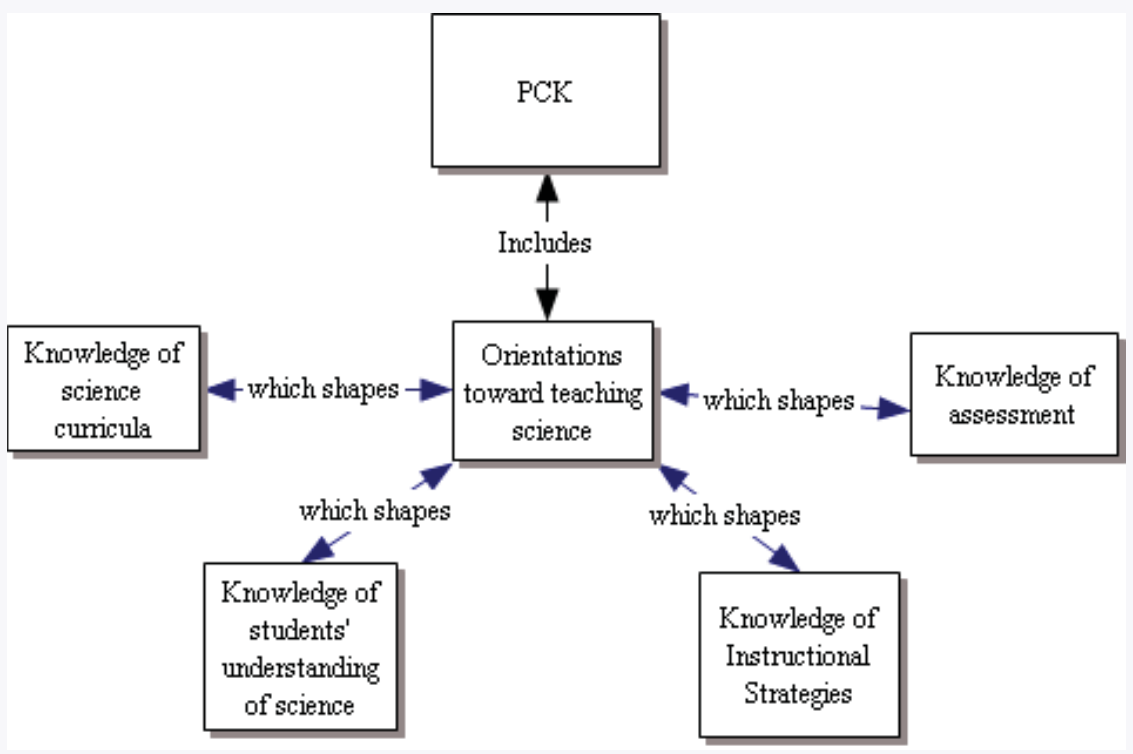


(1987), Grossman (1990), and Tamir (1983). The authors defined five components of PCK for science teaching: 1) orientations toward science teaching, 2) knowledge and beliefs about science curriculum, 3) knowledge and beliefs about assessment in science, 4) knowledge and beliefs about instructional strategies for teaching science, and 5) knowledge and beliefs about students' understanding of specific science topics. The reference to both knowledge and beliefs emphasizes the distinction between knowledge as the "comprehension or awareness of an idea" and belief/disbelief as the personal acceptance or rejection of an idea (Griffin \& Ohlsson, 2001). This conceptualization of PCK is presented in Figure 1. In the following paragraphs we describe each of these components of PCK, and how they can be viewed as "strategic understanding" (i.e., how these components of knowledge can be applied by teachers as professional decision-makers in the classroom context).

The first component is orientations toward teaching science (Anderson \& Smith, 1987) or overarching conception of teaching (Grossman, 1990). This component includes teachers' knowledge and beliefs about the purposes and goals for teaching a specific science topic at a particular grade level (Magnusson et al., 1999). In a strategic view, this component guides teachers' instructional decisions and informs their understandings and practices of the other four components of PCK. Anderson and Smith include four orientations: activity driven, didactic, discovery, and conceptual change, while Magnusson et al. add process, academic rigor, project-based science, inquiry, and guided inquiry. Teachers can simultaneously hold multiple orientations in different situations, such as didactic and inquiry, that may appear to have disparate goals for teaching science (Smith \& Neale, 1989).

The second component of PCK, knowledge of science curriculum, includes the knowledge needed for a specific topic. This knowledge is comprised of the goals and standards (or "big ideas") for a subject, and specific curricular programs and materials. In a strategic view, teachers may need to use or recall knowledge from different subject matter and various curricular materials for specific topics they teach or to answer students' questions.

The third component, knowledge of assessment in science, proposed by Tamir (1983), consists of two categories: knowledge of dimensions of science learning (e.g., knowledge of students' conceptual understanding and scientific practices) and knowledge of assessment methods. From a strategic view, a teacher should know when and how to use each assessment method and how assessment results inform ongoing instructional decisions. Another dimension of this component is knowledge of assessing one's own teaching, or reflection.

The fourth component, knowledge of instructional strategies, is comprised of knowledge of subject-specific and topic-specific strategies. From a strategic perspective, a teacher should be able to decide whether and when each strategy will be useful for a specific teaching situation. A teacher's instructional decisions are closely related to the specific orientation he or she holds for a specific topic or situation. For example, when

- volume 2, no. 2 (Fall 2008) 
teaching electrical circuits, a teacher can choose to use one or more strategies: providing a demonstration, letting students explore and discover, guiding them with questions, and so on.

The last component of PCK is knowledge of students' understanding in a particular subject. This component includes knowledge about students' prior knowledge and common misconceptions, knowledge of contexts that connect learning to students' lives, and knowledge of typical learning progressions, or student trajectories of understanding (Committee on Science Learning, 2007b). A strategic approach to this component will include, for example, decisions about how to address a common misconception and decisions about which context will be appropriate in a diverse classroom or for students in different grade levels.

Table 1. Categories and Indicators for PCK Analysis.

I. Orientations toward the teaching of a particular subject
a. Constructivist framework
b. Conceptual change
c. Inquiry/ Discovery/ Project-based (student-centered)
d. Hands-on/Activity-driven (performing activities without conceptual coherence)
e. Didactic (Teacher-centered - Presenting facts, recall, memorizing, received scientific knowledge)

II. Curricular knowledge for a particular subject
a. Knowledge of learning goals, standards, or big ideas

III. Assessment for a particular subject
a. Assesses students' scientific knowledge (big ideas and understanding)
b. Assesses students' scientific practices (scientific literacy and skills)
c. Informs instructional decisions
d. Ongoing/embedded

IV. Instructional strategies for a particular subject
a. Activities build on each other (activity cycles)
b. Considers students' ideas and experiences
c. Include multiple appropriate representations and learning experiences
d. Instructional decisions consider pros and cons
e. Inquiry application
f. Motivating environment

V. Knowledge of students' understanding in a particular subject
a. Knowledge of common student misconceptions
b. Connected to students' lives (authenticity)
c. Typical student trajectories of understanding (learning progressions) 
Table 1 summarizes, for each of the five categories, a list of each of the subcomponents that help define that category. These are summaries drawn primarily from Magnusson et al. (1999), with additional guidance from other sources (Anderson \& Smith, 1987; Committee on Science Learning, 2007b; Grossman, 1990; Shulman, 1986; Tamir, 1983). The representation of science PCK presented in Table 1 serves as the guiding framework for assessing PCK in the present study.

The development of PCK requires drawing upon knowledge from each of these components. In our professional development model, the goal is to develop teachers' strategic pedagogical content knowledge (i.e., clinical reasoning skills) as well as their conceptual understanding, through a problem-based learning approach. By focusing on "strategic" PCK, we emphasize that teachers need both basic theoretical knowledge as well as applied practical knowledge of science teaching.

\section{Research Questions}

In this study, we report on first-year data from the ongoing five-year design experiment on the effectiveness of the PBL for Teachers Project. This study focused first, on the effect of the intensive two-week summer workshop on teachers' conceptual understanding, and second, on the effect of this workshop and subsequent year of monthly meetings on teachers' PCK. Specifically, our research questions were:

1. Did teachers' conceptual understanding (content knowledge) change during the two-week summer workshop? If so, how did it change?

2. Did teachers' pedagogical content knowledge change during the two-week summer workshop, or during the subsequent year of professional development meetings and self-study? If so, how did it change?

We hypothesized that the explicit focus on content in the content PBL problems and in the teachers' revisions of their own units would lead teachers to develop deeper content understanding. Likewise, we hypothesized that the second-week focus on problems addressing PCK topics, as well as teachers' further work on their unit revisions and classroom teaching problems, would lead to changes in their PCK, especially on subcomponents of PCK that received more attention in the professional development.

\section{Methods}

\section{Research Design}

The designs for research questions 1 and 2 (i.e., for examining teachers' content knowledge and teachers' $\mathrm{PCK}$ ) are slightly different. For content knowledge, we employed a one-group, pretest-posttest design around the treatment of the first week of the summer workshop, which focused on using problem-based learning to deepen teachers' conceptual science understanding (Cook \& Campbell, 1979). The pretest and posttest consisted 
of teachers completing a concept map of the big science ideas associated with the focus science topic they had chosen.

To examine development of teachers'PCK, we employed a multimethod, one-group, repeated-treatment design (Cook \& Campbell, 1979). Multimethods for data collection included creation of concept maps of PCK at three times and composing a paragraph to explain the second map. The three times that the teachers created PCK concept maps were before treatment, after the second week of the summer workshop focusing on using problem-based learning to develop PCK, and after a year of participation in monthly professional development meetings. Though these designs are limited by threats to validity such as other relevant events occurring between the pre and posttests, constraints on our study made these the most practicable designs for our purposes. In particular, our research design efforts were balanced by the main goal of this project, which was to provide effective teacher professional development.

\section{Participants}

Forty-five teachers participated in the first week of the PBL professional development summer 2005 workshop. Of these 45 participants, 22 stayed for the second week of the summer workshop (an optional professional development opportunity). This subset of teachers ( 6 male, 16 female) provided data for the pre-post assessment of conceptual science understanding. Of these 22 teachers, 12 were elementary teachers (grades K-5), 7 were middle school teachers (grades 6-8), and 3 were high school teachers (grades 9-12). The teachers represented multiple districts within several hours' drive of the project's home institution. Of these 22 teachers, 20 ( 5 male, 15 female) completed the pre-post assessment of pedagogical content knowledge during the second week of the workshop. Of these 20 teachers, 14 ( 4 male, 10 female) stayed with the project for the full academic year and completed a year-end assessment of pedagogical content knowledge.

\section{Procedure and Instruments}

In choosing evaluation instruments for our PBL project, we considered multiple challenges, including:

1. Assessing a flexible professional development program that provided the teachers with a large amount of choice and opportunity for self-direction in their learning. As such, no one instrument could be developed to assess teacher learning and knowledge.

2. Assessing outcomes of problem-based learning methods. Previous studies have discussed the difficulties of accurately assessing learning outcomes in a PBL context. Dochy et al. (2003) found that the types of assessments used influence the results. Hmelo-Silver (2004) also demonstrated that traditional measures such as multiple-choice tests may not properly assess the type of deep, flex- 
ible knowledge that PBL has been shown to foster. Because PBL emphasizes contextual richness and the development of conceptual connections (HmeloSilver, 2004; Jones, Rua \& Carter, 1998), we decided that evaluation instruments that emphasized context and encouraged the inclusion of connections among concepts would be appropriate.

3. Measuring changes in pedagogical content knowledge. As a result of its complex structure, evaluation of PCK is complicated (e.g., Kagan, 1990), and conventional assessment methods are not suitable for integrating all aspects of PCK. For example, Baxter and Lederman (1999) suggest that Likert-type self-report scales, multiple-choice items, and short answer formats reflect predetermined descriptions of desired teacher knowledge. These methods narrow the conceptualization of PCK by suggesting that a set of "right answers" exist. In contrast, we needed a measure sensitive to connections among the components of PCK.

\section{Data Sources}

To address the challenges discussed above, and to follow principles for equitable assessment in evaluating teachers (Hough, O'Rode, Terman \& Wineglass, 2007), we chose concept maps as the primary assessment tool in the evaluation of our PBL project. Concept maps allowed us to measure changes in teachers' scientific conceptual understanding and pedagogical content knowledge, and fulfill principles of equity such as following a process that is a valuable learning experience for teachers and challenging teachers to make connections between ideas. The use of concept maps also aligned with a goal which is common to professional development designers, the problem-based learning approach, and pedagogical content knowledge development, that is, providing the teachers with a conceptual tool for examining and reflecting on their own understanding.

An advantage to using concept maps is that they may be used to identify individuals' organizational patterns and essential concepts in the form of nodes around which the knowledge is organized. Therefore, concept maps show both domain-specific knowledge as well as the organization of that knowledge (Kinchin \& Hay, 2000; Novak \& Gowin, 1984; Novak 1990). As an assessment tool, concept maps may be used to document changes in knowledge and understanding over time. According to Edmondson (2000), concept maps may be useful for portraying learning that traditional methods of assessment have not captured effectively, and for assessing types of knowledge that learners bring to bear on specific problems. To examine changes in individual teacher's content and pedagogical content knowledge, we compared pre and post concept maps for each teacher.

To help triangulate teachers' reasoning underlying the maps they drew, we collected short explanations corresponding to the concept map tasks. For some maps (explained below), we asked teachers to write short paragraphs explaining the concepts, connections, and the changes they made in their maps. These served as a second source of data. 


\section{Data Collection}

During the workshop, teachers were organized into three groups according to the broad category of subject-matter they taught (or were interested in focusing on for the workshop): Earth Science, Physics, and Life Science. These groups served as cohorts for the first week.

During the first day of week one, teachers completed a concept map of the "big science ideas" associated with their chosen science topic (e.g., simple machines, ecosystems, moon phases; see directions given to teachers in Appendix B). "Big ideas" refer to the main concepts of science for a specific topic, as defined in Benchmarks for Scientific Literacy (American Association for the Advancement of Science [AAAS], 1993) and the national science education standards (National Research Council, 1996). For example, a big idea in elementary physical science is "some common materials, such as water, can be changed from one state to another by heating or cooling" (National Research Council, p. 127). This map was meant to measure the teachers' conceptual science understanding. Example maps are presented in the results section.

On the last day of the first week, participants were given copies of their maps and asked to add, delete, or make changes to their original maps if they desired. Data were collected at this time, because at the end of the first week, roughly half of the teachers would complete their professional development (the second week was optional). Teachers were also asked to identify and explain their changes in writing. This task was designed to engage participants in conceptualizing their own changing understandings of science, how their students might come to understand the big ideas in science and to provide a basis for the researchers to measure participants' changes in science content knowledge.

During the first day of week two, participants engaged in a short writing assignment designed to elicit their pedagogical content knowledge about their unit; teachers sketched out a vignette of an ideal science classroom, including ideas about "teachers' actions, students' actions, assessments, activities and strategies, and big ideas." Following this activity, they wrote down a few things that were important to keep in mind for the effective teaching of their unit. Participants then drew a concept map of these ideas, which was used as an assessment of pedagogical content knowledge (see Appendix $C$ for directions).

After completing the second PCK concept map, the teachers explained the changes they made and reflected about the process. Our rationale for this concept mapping activity was rooted in the nature of week two, which used the PBL process to pose instructional problems about science teaching to participants (addressing topics of effective assessment, structuring effective inquiry, and facilitating student understanding). We expected that if participants had acquired new conceptual understanding of pedagogical content knowledge constructs (Shulman, 1986, 1987), these changes would be evident in their concept maps. 
A third administration of the concept mapping procedure occurred at the end of the academic year (about 9.5 months after the first concept map), during the final session. Because of time limitations (teachers had to share their own investigations, as well as turn in materials, etc.), conceptual understanding maps were not administered; only PCK maps were completed. Comparing the final PCK maps to the initial ones enabled us to measure changes in teachers' pedagogical content knowledge after one academic year of participation in the project.

\section{Scoring and Analyses}

Maps of conceptual science understanding. Because teachers chose what content area to represent in their maps, their maps addressed twelve different science topics (e.g., phases of the moon, life cycle, electrical circuits, waves), and therefore it was impossible to code all the maps according to the same standards. Raters blindly coded each teacher's two maps, without knowing who the participant was (there was only a number on the maps), which of the two maps was a pre, and which was a post. Using this procedure, raters were able to address the research question (i.e., did teachers learn between the two time points) by focusing on the potential change of each teacher. In order to make decisions about teacher change based upon empirical evidence, raters did not have access to teachers' writings about their changes, nor were they aware which map was pre and which map was post. In some cases, for example, the raters (blindly) judged the pre map to be better (the rating procedure is described in full later in this section). This approach also allowed us to avoid the potential pitfalls of comparing maps across topic areas and teachers (who interpret the concept mapping exercise differently, who have different norms of expressing themselves, and who use different concept mapping conventions), thus avoiding many of the known methodological problems of using concept maps for research (Ruiz-Primo, Shavelson, Li \& Schultz, 2001)

The three raters each had extensive background in science and science education. Two raters with the most appropriate background were chosen for each map based upon its subject matter. It is worth noting that the science concepts depicted in the maps were at the "big ideas" level for K-12 students.

The raters used a rubric to identify which map showed better conceptual understanding using three main criteria: 1) the accuracy of concepts and relationships contained in the maps; 2 ) the quality of concepts contained in the maps, preferring "big ideas" to small ones; and 3) the relationship between the nodes on the maps. For example, two maps may have had the same ideas (nodes), but were arranged (connected) differently such that one reflected a better conceptual understanding of the material.

Each rater chose which of the two maps reflected the best conceptual understanding, using the three criteria, and then holistically and qualitatively rated the degree of difference (no noticeable difference $=0$, small but noticeable difference $=1$, moderate

- volume 2, no. 2 (Fall 2008) 
difference $=2$, large difference $=3$ ). When the two coders differed, we used consensus coding (in all cases the two coders were able to agree on a coding). This scale proved to be reliable. Two researchers used the coding scheme separately to test the reliability of the approach. Their scores were used to compute Cronbach's $\alpha$ inter-rater reliability, arriving at 0.90 , suggesting a very good reliability for the inter-rater scoring (Nunnally, 1978). Disagreements in coding were then resolved by consensus, and consensus scores were used in analysis.

The resulting codes were analyzed statistically and descriptively using a one-sample t-test on the mean rating (testing whether or not the average change was different from 0 ). We provide Cohen's $\partial$ as a descriptive estimate of the overall effect size and a measure of practical significance (Cohen, 1988, 1990).

Pedagogical content knowledge concept maps. In contrast with the content knowledge maps, all teachers addressed the same topic in their PCK maps (i.e., what is good science teaching?). Each map was rated separately, according to the coding scheme in Table 1. The coding scheme, based on an elaborated form of Magnusson et al.'s (1999) conceptualization of PCK for science teachers, nicely describes the activities in the workshops: orientations toward teaching, curricular knowledge, assessment, instructional strategies, and knowledge of student understanding-all with respect to science. Drawing on topics addressed in the PBL workshop, the researchers developed multiple indicators for each category except for curricular knowledge. For example, for assessment, we developed four indicators: 1) assesses students' scientific knowledge, 2) assesses students' scientific practices, 3) assessment informs instructional decisions, and 4) assessment is ongoing or embedded. Following Magnusson et al. (1999), teaching orientations were coded as a component of PCK: identifying inquiry, conceptual change, constructivist, didactic, and activity-driven orientations. Table 1 encapsulates the full list of coding categories.

Two separate analyses of PCK maps were done. The first compares the initial PCK maps with those done at the end of the week two workshop. The second compares the initial PCK maps with those done at the end of the academic year (about 9.5 months later). The number of participants is different for these two analyses: 20 participants for the workshop and 14 for the end of the year analyses (the number of participants decreased during the year due to absences and attrition). We used a four level scale for scoring each indicator or orientation ( 0 if the topic was not present, 1 if the topic was just mentioned, 2 if the topic was partly elaborated, and 3 if the topic was clear and explained).

As an example, Figure 2 presents pre- and post-PCK concept maps of the same participant before and after the workshop. For the category of Curricular Knowledge, and the one indicator "Knowledge of learning goals, standards, or big ideas," the pre-PCK concept map received a score of 0 , because there was no mention of learning goals, standards, or big ideas (or any other equivalent form). The post-PCK map, in contrast, mentions the phrase "big ideas" and even "learning" issues, but because neither term is elaborated, a 
score of 1 is given for Curricular Knowledge. Now consider the fourth criteria of the Assessment category: "assessment is ongoing or embedded." On the pre-PCK map, assessment is mentioned in the context of giving a pre-assessment, and used to "assess progress." This

Figure 2. Examples for a pre (a) and post (b) PCK concept maps of one teacher.

\section{a. pretest concept map}

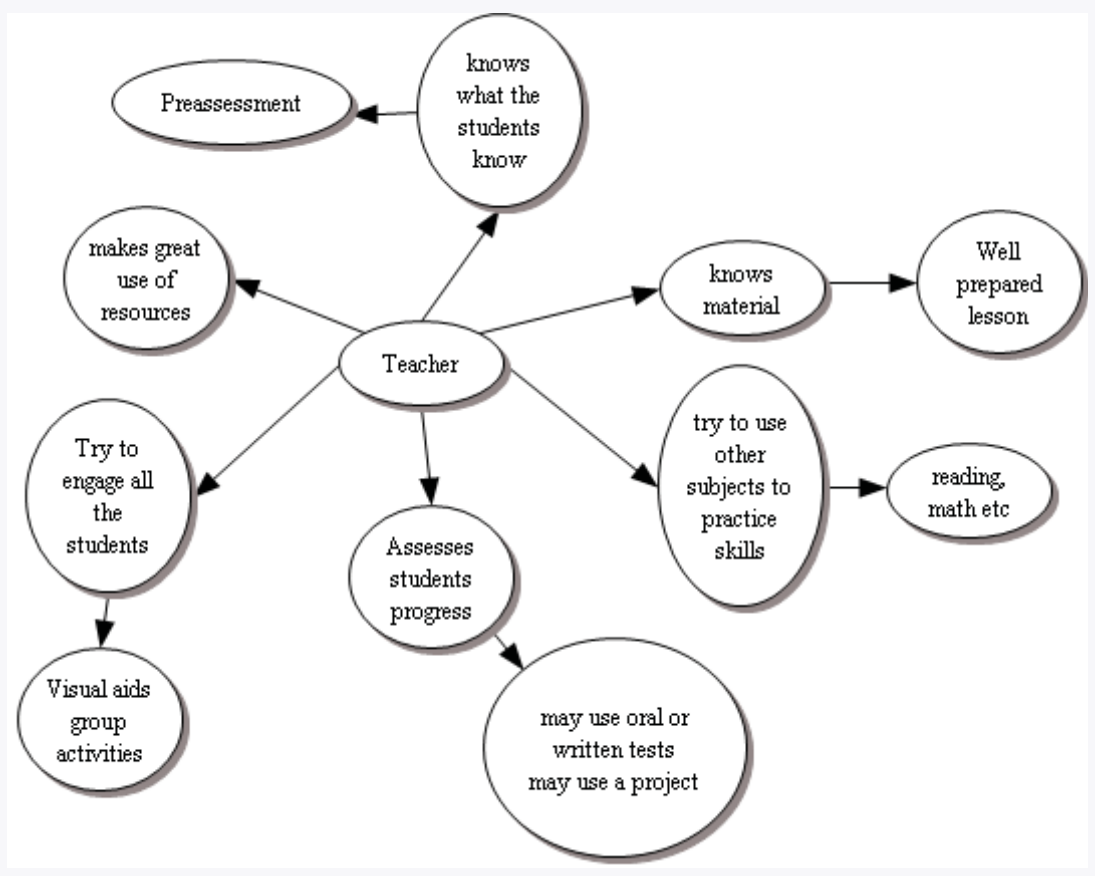

b. posttest concept map

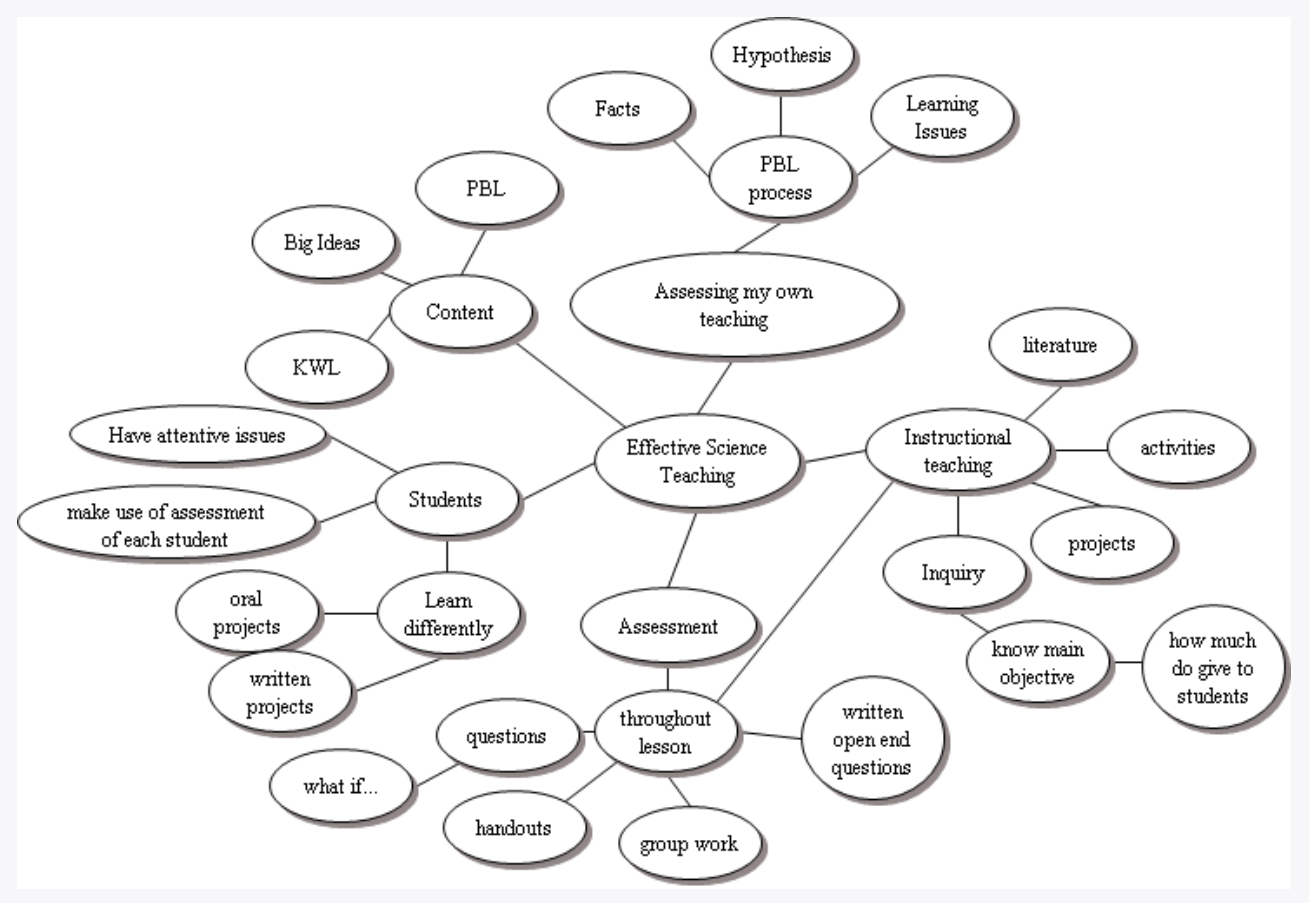

- volume 2, no. 2 (Fall 2008) 
is akin to mentioning ongoing assessment, since it is used to track progress and is used at multiple times, but no elaboration was given on how to do it, or why to do it. Hence a score of 1 was given on the pre-PCK map. The post-PCK map, however, has a fully elaborated depiction of ongoing, embedded assessment. The node "assessment" is expanded to the node "used throughout the lesson," which is further expanded to give details about a variety of assessments and their uses. Furthermore, this teacher also mentions assessment of her "own teaching." Accordingly, a score of 3 was given to post-PCK map on the fourth indicator of assessment.

Each map was independently coded by two researchers. Researchers were blind to the identity of the participants, as well as to which map was the pre-map and which the post. Coding disagreements were resolved by consensus. The indicators for each category were averaged to form a score for each category (except orientations). For example, the four indicators for assessment were averaged to compute a rating for the assessment category. Pre and post maps were compared according to the average score for each category (or, in the case of orientations, according to the score for each indicator). The Cronbach's $\alpha$ inter-rater reliability of the two researchers' coding before agreeing on consensus scores ranged from 0.66 for the category of instructional strategies to 0.87 for the category of knowledge of students (Table 2). Although all other components of the rubric have acceptable coefficients of .75 or higher, the reliability of .66 for instructional strategies is admittedly low. There were very few instances of teachers mentioning instructional strategies, and when they did, it was often in vague terms that made coding difficult. For example, teachers would mention "inquiry" which could be coded as a component of instructional strategies, or a component of teaching orientations. While these coding conflicts resulted in lower reliability for this category, all data for analyses were coded by consensus. And in each case, consensus was reached for every coding decision.

Written descriptions of PCK. We also analyzed teachers' descriptions of what they thought had changed in their maps from the beginning to the end of week two. To analyze these paragraphs, we used the same coding scheme as for the PCK maps, noting

Table 2. PCK Map Coding Inter-rater Reliability

\begin{tabular}{lc}
\hline Item & Cronbach's $\alpha$ \\
\hline I- Orientations & 0.78 \\
II- Curriculum Knowledge & 0.75 \\
III- Assessment & 0.79 \\
IV- Instruct. Strategies & 0.66 \\
V- Knowledge of Students & 0.87
\end{tabular}


the number of teachers who mentioned differences in their maps for each category. This analysis provided insight into the teachers' own reflections on their learning during the professional development workshop. This allowed us to further develop our understanding of teachers' thinking beyond what was available in the representations provided by the concept maps.

\section{Results}

Figure 3. Mean pre-post change on conceptual understanding measure by topic area.

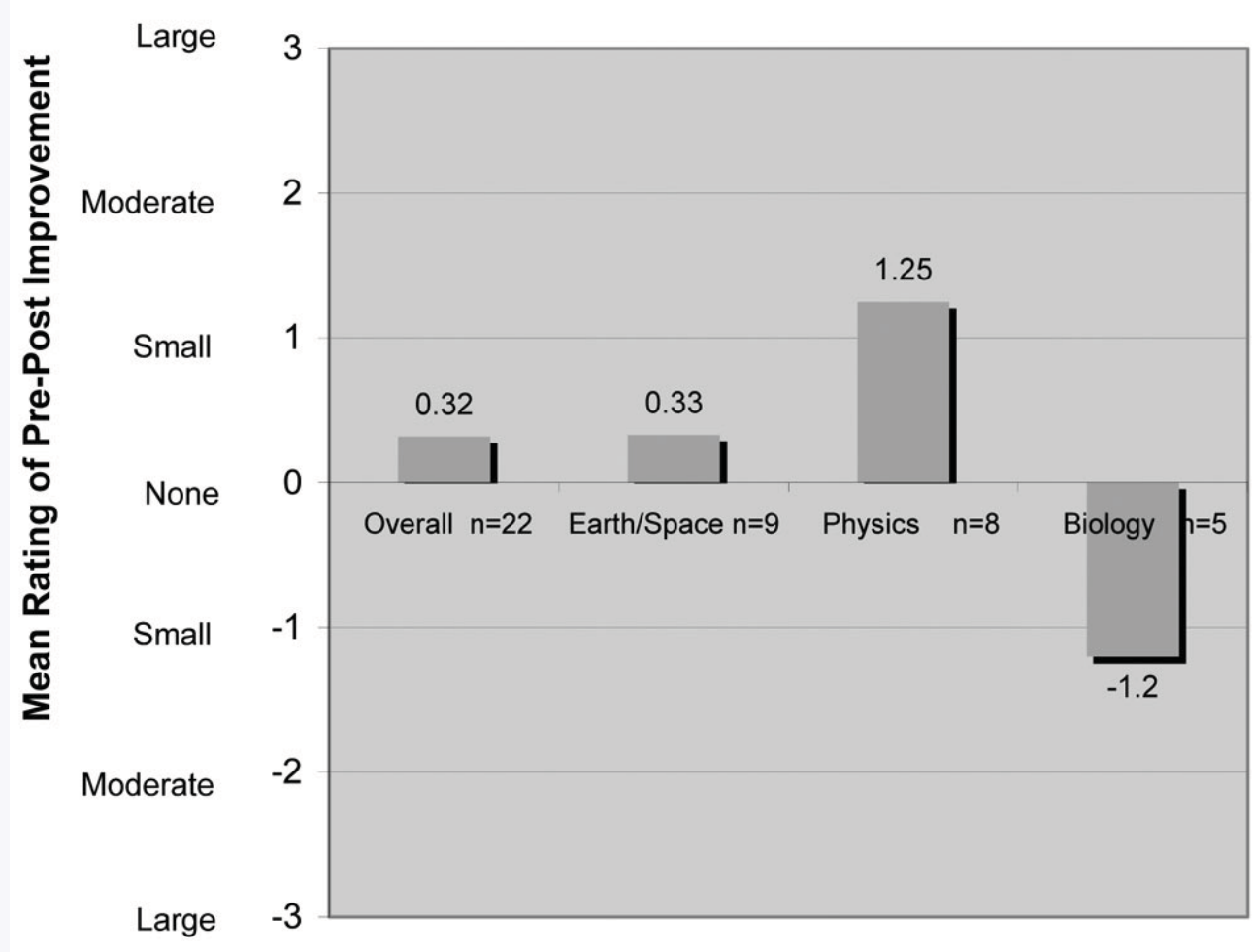

Research Question 1: How Did Teachers' Conceptual Science Understanding Change?

We analyzed twenty-two pairs of pre-post concept maps from the first week of the summer workshop by comparing knowledge and organization for the two maps. For the participants as a group, there was a mean gain of 0.32 points on the 3 point rating scale. This difference is not statistically significant [Mean change $=0.32 t(21)=1.10, p=0.28, \partial=0.23$ ].

Some unique qualities of the PBL workshops suggest, though, that it is important to take a closer look at these data. For the content oriented PBL sessions, our participants were divided into three groups based on science discipline (Life Science, Earth Science, and Physics). Participants in these three groups engaged in related PBL content problems, 
working with different facilitators. Comparisons by group shed light on our findings and suggest a potential explanation for the different outcomes of the three groups. Results by group are shown in Figure 3.

Although there was no overall change in conceptual understanding for all participants, there were changes in individual groups. Neither Earth Science participants nor Life Science participants demonstrated a significant change in conceptual understanding, while the Physics participants did demonstrate a noticeable increase in conceptual understanding [Mean change $=1.25 t(21)=7.64, p<0.01,2=3.84]$. The changes for Physics participants were moderate, and usually did not include new big ideas. Instead, these changes generally included more connections between big ideas and better organization of ideas. For example, one teacher who chose the topic of matter included in her post map additional links between nodes (gas, liquid, solid), showing possible phase changes that were not identified in the pre map.

Several factors may explain the increased demonstration of knowledge in the Physics teachers' concept maps. Differences between the makeup of the teacher groups, their motivations, their conceptual understanding prior to the PD, the design of the problems they encountered, or the interaction between facilitator and learners are all possibilities. When we analyzed the participant application surveys, we found that, compared with the other groups of teachers, teachers in the Physics group rated gaining conceptual science understanding as a more important personal goal for their professional development experience. Thus, their relative gain in conceptual understanding may reflect this group's particular interest in achieving this goal.

Figure 4. Mean pre and 4 day post ratings on sub-components of $P C K$.

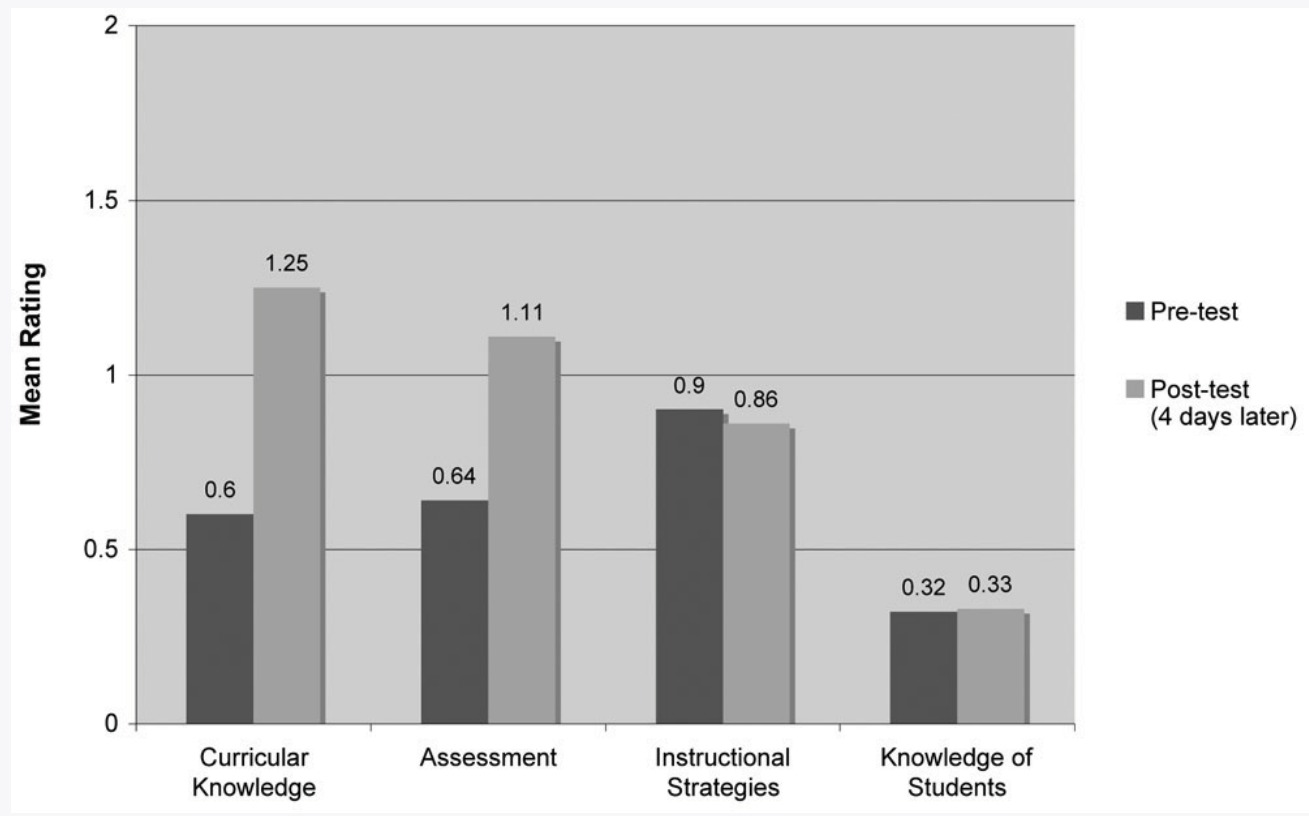




\section{Research Question 2: How Did Teachers' Pedagogical Content Knowledge Change?}

To analyze teachers' pedagogical content knowledge maps, we examined the categories of 1) pedagogical orientations, 2) curricular knowledge, 3) assessment, 4) instructional strategies, and 5) knowledge of students, both at the beginning and end of the workshop and at the end of the year.

Results following the week two workshop (Figure 4) demonstrated positive change in two PCK categories: curriculum knowledge [Mean change $=0.65 t(19)=3.11, p=.01$, $\partial=0.93$ ], and knowledge of assessment [Mean change $=0.47 t(19)=3.28, p=<.01, \partial=0.89$ ]. There were no significant changes in teachers' pedagogical orientations between the preand post-maps, either after the week two workshop or at the end of the year. The two orientations most often described in teachers' maps were constructivism and inquiry. No significant changes were found for the categories of instructional strategies and knowledge of students. Curriculum knowledge and assessment were pedagogical topics that were emphasized in the second week workshop, and associated changes in teachers' maps indicated the participants were, at the very least, developing an increased awareness of the importance of these components of pedagogy in their teaching practice. Instructional strategies were emphasized in the workshop but no significant change in this component was found. A possible explanation is that teachers were already moderately knowledgeable about this area of PCK when they entered the workshop (the overall pre-map average for instructional strategies is the highest compared to the other three categories), and therefore the contribution of the workshop to this knowledge was relatively small.

The changes found in the component "knowledge of assessment" in post-maps included, for example, new nodes like "assessing my own teaching" and "embedded assessment" that did not appear in pre-maps, or new links that reflected understanding of the role of assessment, like linking assessment back to "teacher readiness" to show how assessment may inform teachers' decisions.

We found a similar trend for PCK when we looked at changes between the teachers' pre-maps and those completed at the end of the academic year. That is, teachers showed a remarkably similar significant change in knowledge about assessment [Mean change $=0.45$ $t(14)=2.91, p=0.01,2=0.80$ ]. Again, there is a similar magnitude of change for curricular knowledge (and a similar level of practical significance); however, this change was not statistically significant [Mean change $=0.50 t(14)=1.84, p=0.09, \partial=0.58$ ]. The instructional strategies and knowledge of students measures, again, showed little change. A closer look into multiple data sources of two individuals is being done through case studies to learn about the changes in each PCK component that individual teachers underwent during participation in the project (Weizman, Lundeberg, Koehler \& Eberhardt, 2007).

- volume 2, no. 2 (Fall 2008) 
Figure 5. Mean pre-post changes of sub-components of PCK after 4 days and after the academic year.

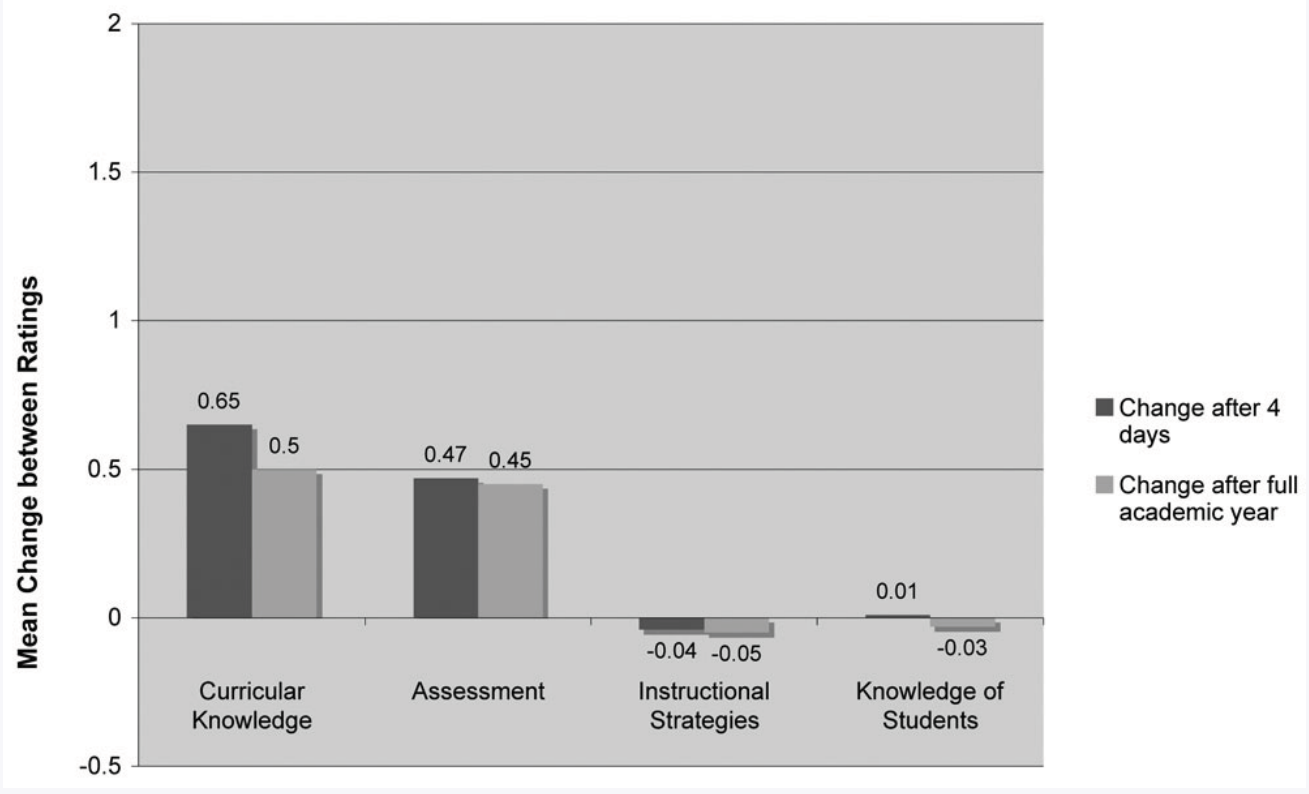

As Figure 5 illustrates, the findings are consistent one academic year later. There is growth in both comparisons in measures of curricular knowledge and assessment, and little to no change for instructional strategies or knowledge of students.

\section{Written Descriptions of PCK}

Results from teachers' paragraphs completed with their PCK maps at the end of week two (i.e., their perceived learning gains from the week two professional development) showed some similarities and some differences with the concept map analysis. Table

Table 3. Number of Teachers Who Mentioned each Category in Teachers' Paragraphs

\begin{tabular}{lcc} 
Category & $\begin{array}{c}\text { Number of teachers } \\
\text { who mentioned }\end{array}$ & $\begin{array}{c}\text { Percentage of teachers } \\
\text { who mentioned }\end{array}$ \\
\hline I- Orientations & 5 & $25 \%$ \\
II- Curriculum Knowledge & 5 & $25 \%$ \\
III- Assessment & 12 & $60 \%$ \\
IV- Instructional Strategies & 14 & $70 \%$ \\
V- Knowledge of Students & 6 & $30 \%$ \\
Other Perceived Learning Outcomes & 11 & $55 \%$
\end{tabular}


3 shows the number of teachers who mentioned each of the categories of PCK that we coded. The table also includes the number of teachers who mentioned learning gains that did not match our PCK learning goals.

In some instances, teachers' perceived learning outcomes were disparate from or not clearly tied to our project goals. In the paragraphs, eleven teachers mentioned changes in their maps that either did not match a category of our learning goals (e.g., one teacher wrote that she added science process skills to her map), or were too unclear to match with a category (e.g., one teacher mentioned use of tools, without specifying which tools or whether this referred to teachers or students using tools). Overall, however, the paragraph data suggest that the teachers perceived numerous learning outcomes from the workshop, the majority of which matched our project goals.

A clear similarity between the paragraph and concept map findings is evident for the category of assessment. Twelve of the twenty teachers mentioned aspects of assessment as representing new concepts in their second maps. Further, many of these teachers wrote about complex instructional purposes for assessment in their paragraphs. For example, one teacher wrote, "I have mainly used a comprehensive assessment at the end of a unit to analyze student learning. I need to focus more on using assessment for other reasons...like readjusting the lesson to accommodate misconceptions." These twelve teachers' comments provide additional support for our concept map findings that the teachers gained significantly in their understandings of assessment during the professional development workshop.

Curricular knowledge, which was the second category showing significant change for the map analyses, was not mentioned as frequently in the teacher paragraphs as assessment. Five of the twenty teachers each made one comment related to curricular knowledge in the paragraphs. The moderate comments about curricular knowledge in the paragraph data suggest that this was an area of perceived teacher learning, but perhaps not quite as salient an area as assessment.

Although instructional strategies was not a category for which we found a significant change in our analysis of the concept maps, the teachers expressed a sense of having gained a considerable knowledge of instructional strategies in their paragraphs. Fourteen teachers mentioned instructional strategies they believed they had added to their second concept maps. Common examples included collaborative or cooperative group work, which was mentioned by three teachers; and inquiry strategies such as gathering data or recording results, which was also mentioned by three teachers. The fact that instructional strategies were so prominent in teachers' paragraphs, while not significant in our map analyses likely reflects the differences in our intents. In our indicator coding, following the goals of the professional development, we looked for strategic aspects of instruction such as sequencing activities to develop student understanding, inquiry instructional strategies, considering students' ideas, and so on. In contrast, teachers sometimes mentioned 
instructional approaches that were not a focus for professional development, such as using discussions or collaborative group work. It is possible that these other strategies represent "modeled" rather than explicitly emphasized practices that teachers noticed during the workshop; the teachers did engage in a large amount of collaborative work and discussion during the workshop. Thus, the participants perceived that they gained understanding of instructional strategies as a result of the workshop, but their perceptions did not, in all cases, closely match the project's primary instructional strategy goals.

\section{Discussion}

We are both discouraged and encouraged by the findings. It is somewhat disappointing to find that only one group developed conceptual understanding, and that teachers did not develop PCK components of instructional strategies or knowledge of students, at least as measured here (and we acknowledge this is possibly a limitation of the measurement). Furthermore, it is somewhat disappointing to find that the monthly meetings, self-study between meetings, and the continuing attention to professional development did not lead to increased gains on any measure during the academic year. In a more positive light, however, finding that some teachers were able to learn conceptual knowledge and that some of the PCK learning goals (i.e., assessment and curricular knowledge) were realized are encouraging results for the first year of the professional development. We are also encouraged that, for the most part, teachers were able to maintain any gains established during the intensive summer workshop and that these changes were not simply a halo effect of putting the assessment so close to the intensive, initial two-week intervention.

These results are consistent with the literature on PBL. Previous studies have shown that a PBL approach may be better suited to improving clinical reasoning skills (analogous to strategic PCK) rather than conceptual understanding (Albanese \& Mitchell, 1993; Harrington, 1995; Hmelo-Silver, 2004). The end-of-year PCK concept maps showed significant changes in knowledge of assessment, which is a main component of clinical reasoning professional practitioners must evaluate and reflect on their own decisions constantly.

The growth we found in curricular knowledge and assessment issues corroborates well with our own observations of the first-year model in practice. Teachers began to develop assessment methods both to evaluate their students and to reflect on their own practice. During the meetings, as teachers talked about their own classrooms (and often shared video of their teaching), assessment was a frequent topic of conversation. Also consistent with the practices of PBL, teachers established a norm that asked for evidence to support any hypothesis that they had for the classroom issues they were investigating individually. Curricular knowledge was also important to the PBL activities of these teachers. Curriculum was part of every classroom lesson a teacher would talk about (or show as part of their video presentation), but was harder to share with the group mem- 
bers, because teachers in each group differed by grade level and subject matter. In short, although curricular topics were mentioned, they were not discussed as frequently as assessment issues, and this may account for why only the assessment component gains remained statistically significant after the academic year.

We also learned much about the challenges and limitations of assessing teacher knowledge while studying a model of teacher professional development that is continually being refined. These issues represent the challenges as well as the strengths of doing design-based research. That is, that research can inform implementation and vice versa. These issues are highlighted prominently in our need to measure teachers' knowledge in the complex and flexible context of our professional development program. Although we have found concept maps to be useful for this purpose, we also acknowledge that these maps can be difficult to assess (i.e., note our adequate, but in some cases not excellent inter-rater reliabilities). Another challenge we encountered was that we used instruments to measure teachers' changes in knowledge at only three points over the course of a yearlong professional development program. More frequent and different types of measures might have provided additional means for examining teacher learning at a finer scale. Further analysis of the first year of professional development suggested that not all of the conceptual learning and PCK learning occurring was captured by our measures. For example, every day during the first week of the workshop, teachers discussed a problem designed to deepen their knowledge about a science topic (e.g., circuits), but the science content assessment only examined their understandings of the self-selected unit they were revising.

In response to these challenges, changes have been implemented in the PBL Project for Teachers. Instead of separate "heavy" assessments at a few selected moments, we are using embedded "lighter" assessments that are integrated with each problem scenario through which the teachers work. For example, a problem on circuits has an embedded pre and post test as part of the problem (Mikeska, Lundeberg, Koehler, \&Weizman, 2007). The format of these assessments ranges from short writing to multiple choice. Thus, we have found it possible and productive to administer to the teachers more assessments, more often, and more naturally in applied settings. In this way, we are better able to measure both changes in teacher understanding, as well as the design and effectiveness of the individual problem scenarios.

In addition, we have also used findings from the initial project year to inform the design of our professional development with the teachers. In addition to embedding assessments within problems, we have responded to the limited changes in strategic pedagogical content knowledge by more closely connecting the teachers' work on their units with the week one and week two workshop topics. We have also moved towards standardizing the approach across the different content cohorts and facilitator pairings (Oslund et al., 2006). By interspersing facilitator-supported teacher work on individual 
units with time spent on group pedagogical PBL problems, we hope that the teachers will be able to better integrate what they learn in their group work with their individual strategic PCK development.

\section{Conclusion}

In this study, we used concept maps to explore changes in participants' conceptual science understanding and pedagogical content knowledge as a result of participating in problem-based learning professional development. Teachers developed understanding of components of pedagogical content knowledge, especially related to clinical reasoning, such as knowledge of assessment. Gains of conceptual science understanding were limited to one group of teachers. Several factors likely underlie this variability, including the individualized nature of teachers' subject-matter investigations, differing goals for professional development, and differing group dynamics. Our findings support previous research that suggests that PBL may be better suited for developing reasoning skills than subject-matter knowledge (Dochy et al., 2003).

Our attempts to measure changes in teachers' knowledge, however, revealed important limitations and challenges in assessing teacher knowledge while studying teachers' professional development. Addressing these challenges and limitations through continuing cycles of professional development enactment, research, reflection, and modification are leading to improvements in both the professional development we provide to participating teachers and in the contributions to research and theory we are able to generate through our work. Through ongoing cycles of design-based research, we will continue to learn more effective ways to develop teachers' science content knowledge and strategic pedagogical content knowledge through problem-based learning professional development.

\section{Acknowledgements}

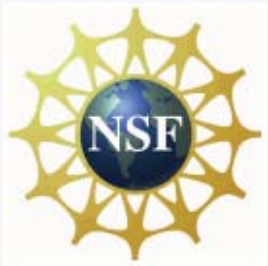

This material is based upon work supported in part by the National Science Foundation, under special project number ESI - 0353406 as part of the Teacher Professional Continuum program.

Any opinion, finding, conclusions or recommendations expressed in this publication are those of the authors and do not necessarily reflect the views of any of the supporting institutions.

The authors would like to acknowledge the contributions of the entire project staff, whose work contributed both practically and conceptually to the design and implemen- 
tation of the PBL for Teachers Project. In particular, we would like to acknowledge the contributions of Shinho Jang and Joyce Parker who contributed substantially to the design and implementation of the concept map assessment approach.

\section{References}

American Association for the Advancement of Science. (1993). Benchmarks for science literacy. New York: Oxford University Press.

Albanese, M. A., \& Mitchell, S. (1993). Problem based learning: A review of literature on its outcomes and implementation issues. Academic Medicine, 68(1), 52-81.

Allen, D. E., Duch, B. J., Groh, S. E., Watson, G. B., \&White, H. B. (2003). Scaling up research-based education for undergraduates: Problem-based learning. In L. Kauffman \& J. E. Stocks (Eds.), Reinvigorating the undergraduate experience: Successful models supported by NSF's AIRE/ RAIRE program. Washington, DC: Council on Undergraduate Research. Retrieved August 22, 2007, from http://www.cur.org/publications/aire_raire/delaware.asp

Anderson, C. W., \& Smith, E. L. (1987). Teaching science. In V. Richardson-Koehler (Ed.), Educators handbook, a research perspective (pp. 84-111). New York: Longman.

Barnett, J., \& Hodson, D. (2001). Pedagogical content knowledge: Toward a fuller understanding of what good science teachers know. Science Education, 85(4), 426-453.

Barrows, H. S., \& Tamblyn, R. M. (1980). Problem-based learning: An approach to medical education. New York: Springer.

Baxter, J. A., \& Lederman, N. G. (1999). Assessment and measurement of pedagogical content knowledge. In J. Gess-Newsome \& N. G. Lederman (Eds.), PCK and science education (pp. 147-161). The Netherlands: Kluwer Academic Publishers.

Butler, S. M. (2003). Designing a technology-based science lesson: Student teachers grapple with an authentic problem of practice. Journal of Technology and Teacher Education, $11(4), 463-481$.

Capon, N., \& Kuhn, D. (2004). What's so good about problem-based learning? Cognition and Instruction, 22(1), 61-79.

Chernobilsky, E., DaCosta, M. C., \& Hmelo-Silver, C. E. (2004). Learning to talk the educational psychology talk through a problem-based course. Instructional Science, 32(4), 319-356.

Cobb, P. (2001). Supporting the improvement of learning and teaching in social and institutional context. In S. M. Carver \& D. Klahr (Eds.), Cognition and instruction: Twenty-five years of progress (pp. 455-478). Mahwah, NJ: Erlbaum.

Cohen, J. (1988). Statistical power analysis for the behavioral sciences (2nd ed.). Hillsdale, NJ: Lawrence Erlbaum Associates, Inc.

Cohen, J. (1990). Things I have learned (so far). American Psychologist, 45(12), 1304-1312.

Collins, A. (1992). Towards a design science of education. In E. Scanlon \&T. O'Shea (Eds.), New directions in educational technology (pp. 15-22). New York: Springer-Verlag.

Committee on Science Learning (2007a). Supporting science instruction. In R. Duschl, H. Schweingruber \& A. Shouse (Eds.), Taking science to school: Learning and teaching science in grades K-8 (pp. 286-316). Washington, DC: National Academies Press.

- volume 2, no. 2 (Fall 2008) 
Committee on Science Learning (2007b). Learning progressions. In R. Duschl, H. Schweingruber \& A. Shouse (Eds.), Taking science to school: Learning and teaching science in grades K-8 (pp. 211-250). Washington, DC: National Academies Press.

Cook, T. \& Campbell, D. (1979). Quasi-experimentation:Design \& analysis issues for field settings. Boston: Houghton Mifflin Company.

Darling-Hammond, L. \& Ball, D. (1998). Teaching for high standards: What policymakers need to know and be able to do. Philadelphia, PA: Consortium for Policy Research in Education.

Derry, S. J., Seymour, J., Fassnacht, C., \& Feltovich, P. (2001). Tutoring and knowledge construction during problem-based learning: An interaction analysis. Paper presented at the National Association for Research in Science Teaching, St. Louis, MO.

Design-Based Research Collective. (2003). Design-based research: An emerging paradigm for educational inquiry. Educational Researcher,32(1), 5-8.

Dochy, F., Segers, M., Van den Bossche, P., \& Gijbels, D. (2003). Effects of problem-based learning: A meta-analysis. Learning and Instruction, 13(5), 533-568.

Duch, B. J. (2001). Writing problems for deeper understanding. In B. J. Duch, S. E. Groh \& D. E. Allen (Eds.), The power of problem-based learning (pp. 47-58). Sterling, VA: Stylus Publishing.

Edmondson, K. M. (2000). Assessing science understanding through concept maps. In J. J. Mintzes, J. H. Wandersee, \& J. D. Novak (Eds.), Assessing science understanding. A human constructivist view (pp. 15-40). San Diego, CA: Academic Press.

Griffin, T. D \& Ohlsson, S. (2001). Beliefs vs. knowledge: A necessary distinction for predicting, explaining and assessing conceptual change. Presented at the 23rd Annual Conference of the Cognitive Science Society: Edinburgh, Scotland.

Grossman, P. (1990). The making of a teacher:Teacher knowledge and teacher education. New York: Teachers College Press.

Harrington, H. L. (1995). Fostering reasoned decisions: Case-based pedagogy and the professional development of teachers. Teaching and Teacher Education, 11(3), 203-214.

Hmelo-Silver, C. (2004). Problem-based learning:What and how do students learn? Educational Psychology Review, 16(3), 235-266.

Hough, S., O'Rode, N., Terman, N., \& Weissglass, J. (2007). Using concept maps to assess change in teachers' understandings of algebra: a respectful approach. Journal of Mathematics Teacher Education, 10(1), 23-41.

Jones, M. G., Rua, M. J., \& Carter, G. (1998). Science teachers' conceptual growth within Vygotsky's zone of proximal development. Journal of Research in Science Teaching, 35(9), 967-985.

Kagan, D. M. (1990). Ways of evaluating teacher cognition: Inferences concerning the Goldilocks Principle. Review of Educational Research, 60(3), 419-469.

Kinchin, I., \& Hay, D. B. (2000). How a qualitative approach to concept map analysis can be used to aid learning by illustrating patterns of conceptual development. Educational Research, 42(1), 43-57.

Levin, B. (1995). Using the case method in teacher education: The role of discussion and experience in teachers' thinking about cases. Teaching and Teacher Education, 11(1), 63-79. 
Levin, B. (Ed.). (2001). Energizing teacher education and professional development with problembased learning. Alexandria, VA: Association for Supervision and Curriculum Development.

Loucks-Horsley, S., Love, N., Stiles, K. E., Mundry, S., \& Hewson, P. W. (2003). Designing professional development for teachers of science and mathematics. Thousand Oaks, CA: Corwin Press, Inc.

Magnusson, S., Krajcik, J., \& Borko, H. (1999). Nature, sources, and development of pedagogical content knowledge for science teaching. In J. Gess-Newsome \& N. G. Lederman (Eds.), Yearbook of the association for the education of teachers of science. Boston: Kluwer.

Mayo, P., Donnelly, M. B., Nash, P. P., \& Schwartz, R. W. (1993). Student perceptions of tutor effectiveness in problem based surgery clerkship. Teaching and Learning in Medicine, 5(4), 227-233.

Mikeska, J. N., Lundeberg, M. A., Koehler, M. J., \&Weizman, A. (2007, April). Designing teaching dilemmas for problem-based learning professional development. Roundtable discussion at the 2007 Annual Meeting of the American Educational Research Association, Chicago, IL.

Mishra, P., \& Koehler, M. J. (2006). Technological pedagogical content knowledge: A framework for teacher knowledge. Teachers College Record, 108(6), 1017-1054.

National Research Council (1996). National science education standards. Washington, DC: National Academy Press.

National Research Council (2000). Inquiry and the national science education standards. Washington, DC: National Academy Press.

National Staff Development Council (2001). Standards for staff development. Oxford, OH: National Staff Development Council.

Newman, M. (2004). Problem-based learning: An exploration of the method and evaluation of its effectiveness in a continuing nursing education program. London: Middlesex University.

Newman, M., Ambrose, K., Corner, T., Quinn, S., Wallis, S., Tymms, P. (2001, July). The project on the effectiveness of problem-based Learning (PEPBL): A field trial in continuing professional education. Paper presented at the 3rd International Interdisciplinary Conference on Evidence-Based Policies and Indicator Systems Conference, Durham, UK.

Novak, J. D. (1990). Concept mapping: a useful tool for science education. Journal of Research in Science Teaching, 27(10), 937-949.

Novak, J. D., \& Gowin, D. B. (1984). Learning how to learn. Cambridge, UK: Cambridge University Press.

Nunnally, J. C. (1978). Psychometric theory. New York: McGraw-Hill.

Oslund, J. A., Low, M., Mikeska, J. N., Weizman, A., Lundeberg, M., Koehler, M. J., \& Eberhardt, J. (2006, April). Creating problems for teachers: Research on constructing problem-based materials to enhance science content knowledge. Paper presented at the Annual Meeting of the American Educational Research Association, San Francisco, CA.

Reich, R. (1990). Redefining good education: Preparing students for tomorrow. In S. B. Bacharach (Ed.), Education reform: Making sense of it all. Boston: Allyn and Bacon.

- volume 2, no. 2 (Fall 2008) 
Ruiz-Primo, M. A., Shavelson, R. J., Li, M., \& Schultz, S. E. (2001). On the validity of cognitive interpretations of scores from alternative concept-mapping techniques. Educational Assessment, 7(2), 99-141.

Sage, S. (2001). Using problem-based learning to teach problem-based learning. In B. B. Levin (Ed.), Energizing teacher education with professional development with problem-based learning (pp. 87-107). Alexandra, VA: Association for Supervision and Curriculum Development.

Scaffa, M. E., \& Wooster, D. M. (2004). Effects of problem-based learning on clinical reasoning in occupational therapy. American Journal of Occupational Therapy, 58(3), 333-336.

Schön, D. A. (1983). The reflective practitioner: How professionals think in action. London:Temple Smith.

Segall, A. (2004). Revisiting pedagogical content knowledge: The pedagogy of content/ the content of pedagogy. Teaching and Teacher Education, 20(5), 489-504.

Shulman, L. S. (1986). Those who understand: Knowledge growth in teaching. Educational Researcher, 15(2), 4-14.

Shulman, L. S. (1987). Knowledge and teaching: Foundations of the new reform. Harvard Educational Review, 57(1), 1-22.

Smith, D. C., \& Neale, D. C. (1989). The construction of subject matter knowledge in primary science teachers. Teaching and Teacher Education, 5(1), 1-20.

Tamir, P. (1983). Inquiry and the science teacher. Science Education, 67(5), 657-672.

Van Driel, J. H., Verloop, N., \& de Vos, W. (1998). Developing science teachers' pedagogical content knowledge. Journal of Research in Science Teaching, 35(6), 673-695.

Van Zee, E. H., Lay, D. \& Roberts, D. (2003). Fostering collaborative inquiries by prospective and practicing elementary and middle school teachers. Science Education, 87, 588-612.

Veal, W. R., \& MaKinster, J. G. (1999). Pedagogical content knowledge taxonomies. Electronic Journal of Science Education 3(4).

Weizman, A., Lundeberg, M., Koehler, M., Eberhardt, J., The Influence of Problem Based Learning Professional Development on Science Teachers'Pedagogical Content Knowledge. (2007, August). Paper presented at the NARST session at the annual meeting of the European Science Education Research Association, Malmo, Sweden.

Zeichner, K., \& Liston, D. (1996) Reflective teaching: An introduction. Hillsdale, NJ: Lawrence Erlbaum.

Zimmaro, D. M., \& Cawle, J.M. (1998). Concept map module. Schreyer Institute for Innovation in Learning, Pennsylvania State University. Available at http://www.inov8.psu.edu/facculty/cmap.htm

Ayelet Weizman was a Visiting Assistant Professor in the Teacher Education Department at Michigan State University on 2005-2008, and is currently working at the Department of Science Teaching at Weizmann Institute of Science. Her research addresses science teachers' professional development, reform-based curriculum and integration of formal and informal learning environments.

Dr. Beth Covitt is a Visiting Assistant Professor in Teacher Education at Michigan State University. Her research addresses science education professional development and environmental science literacy. 
Matthew J. Koehler is an Associate Professor in the Educational Psychology and Educational Technology program in the College of Education at Michigan State University. His research and teaching focus on how an understanding the affordances and constraints of new technologies can inform the design of innovative learning environments and the professional development of teachers.

Mary Lundeberg is a Professor in the Teacher Education and Educational Psychology Departments in the College of Education at Michigan State University. Her research interests include problem-based and case-based pedagogy in teacher education and science, interactive multimedia environments, scientific literacy, and cultural and gender influences in confidence.

Joy Oslund is a doctoral candidate in the Curriculum, Teaching, and Educational Policy Department at Michigan State University. Her research interests include the social construction of identity and knowledge in mathematics teacher education and professional development.

Mark Low anticipates completing his Ph.D. by May of 2009; he is studying the effects of social networks on early career teachers'levels of commitment to their schools and the profession. His research interests include educational policy, school and teacher practices, and the social context of education.

Jan Eberhardt is the Assistant Director of the Division of Science and Mathematics Education at Michigan State University. Her research interest is understanding and developing innovative and effective models of professional development and studying the impact of professional development on science teaching and learning.

Mark Urban-Lurain is the Director of Instructional Technology Research \& Development in the Division of Science and Mathematics Education at Michigan State University. His research interests are in the interrelationships among theories of cognition, the design of instructional technology and the role of technology in educational improvement and reform.

Correspondence concerning this article should be addressed to Ayelet Weizman, 330 Erickson Hall, Department of Teacher Education, Michigan State University, East Lansing, Ml 48824-1316.

- volume 2, no. 2 (Fall 2008) 


\section{Appendix A}

\section{Example Problems}

\section{Example of a Content Problem from Week One: Blood Doping}

Bicyclist Tyler Hamilton, one of Lance Armstrong's main rivals, was banned from competition last fall when he failed a blood test for "blood doping," an illegal performanceenhancing procedure. He vehemently denied the charges, claiming that he was " $100 \%$ innocent." In the weeks and months that followed, a debate raged in the media. Some experts claimed that the blood test was done sloppily; others that it wasn't a reliable test to use in the first place because several other factors could contribute to a false positive result; and others that the most likely explanation was that Hamilton was, in fact, blood doping.

Sheila has students in her class who are following this debate in the media, taking emotionally charged positions on Tyler Hamilton's guilt or innocence. How can she use the debate to respond to her students, and to engage them in the study of science?

\section{Example of a Teaching Problem from Week Two: Circuits and Pathways}

Context.The principles of electricity were the focus for my group of 30 fourth-grade students in a public elementary school in Castro Valley, California during the month of March. I began the unit with a questionnaire asking students, "Where in your house do you find electricity? How do you use it? What might happen if your flashlight stops working?" I started by having the students learn about things that were more familiar to them and then moved to more complex ideas. First, the students made posters of ways that they use electricity in their lives. Then, students experimented with a variety of materials and focused on one challenge: lighting a bulb using a battery, bulb, and wire. They also used a battery, wires, and a motor to make the drive shaft on the motor turn in a clockwise and counterclockwise fashion. After that, they moved to learning about and constructing series and parallel circuits. My goal was for students to come away with an understanding of some of the basic principles of electricity, including how circuits work, how circuits do not work, and something about the flow of current. I also wanted them to have the experience of designing and carrying out their own experiments.

Objective.Students will be able to construct a simple electric circuit that provides a pathway so that current can move between a source (battery) and an object (bulb and/ or bell). Students will be able to identify and describe how various types of electrical circuits (i.e., series and parallel) provide a means of transferring and using electrical energy to produce light.

Teaching Dilemma.I think that it's important for students to take responsibility for their 
own learning and to learn to think critically, to learn to question and to become excited about learning and excited about what they see happening in the world. When they have their hands on the materials and are able to speak with one another, they're in control. After the students had an opportunity to create parallel and series circuits, they noticed that the bulbs in the parallel circuit were brighter than the bulbs in the series circuit. Asking the students to explain their thinking led to a variety of ideas for this observation.

Focus Question. How might a teacher move his or her students from vague ideas to a more scientific understanding?

Product. A recommendation for how this teacher might move her students to a more scientific understanding of electricity.

\section{Appendix B}

\section{Concept Maps: Professional Working Conference}

Directions: Design a concept map for your unit that displays your understanding of the science concepts. The following instructions are provided to guide your work.

\section{Identify the important terms or concepts that you want to include on your map.}

o Please include:

o science concepts you will be teaching

o examples, experiences that you may use to illustrate the concepts

2. Use circles, ovals, or other shapes to enclose each important term or concept.

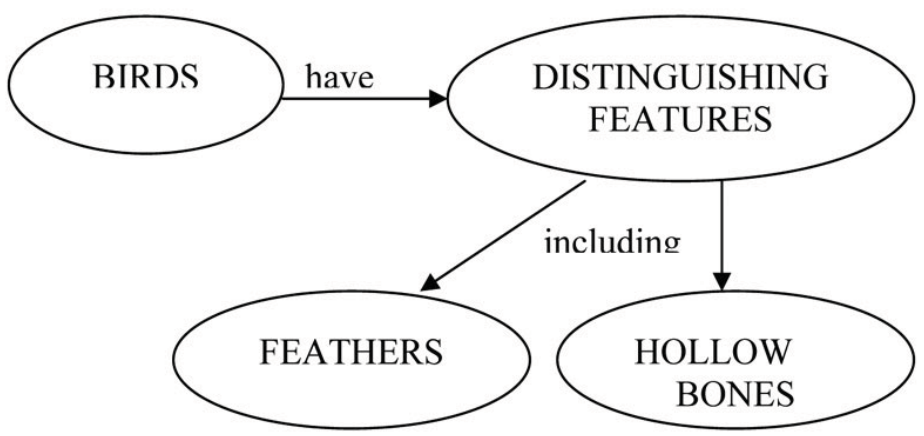

o Each circle, oval or other shape should enclose only one term or concept. However, terms can be more than one word.

o You may choose to use any arrangement of the shapes that you think is appropriate.

3. Use lines with single-headed arrows to link terms that are related.

o Each line should link only two concepts.

o However, there is no limit to the number of links stemming from or leading to 
any one term.

4. Use a word or phrase of words as a label along each line to designate the relationship between each two connected terms. Each set of linked ovals and arrow labels should make a complete sentence.

5. Work and rework your map until you believe it gives an accurate picture of your understanding of:

0 the important ideas involved, and

0 the relationships that exist among them.

Adapted from: Zimmaro, D. M., \& Cawle, J. M. (1998). Concept map module [Online]. Schreyer Institute for Innovation in Learning, The Pennsylvania State University. Available at: http://www.inov8.psu.edu/ facculty/cmap.htm.

Appendix C

\section{What is Effective Science Teaching?}

If you were to peek into the classroom of an effective and engaging science teacher teaching a topic in your unit, what would you see? On a separate piece of paper, write a onepage vignette of an episode in this science teacher's classroom. Assume the conditions and situations are realistic. In your narrative of this scene, try to include:

- the teacher's actions and intentions

- students' actions

- assessment of the students' thinking

- activities and teaching strategies

- big ideas

Below list what you think are the necessary components of effective science teaching. Organize the components above into a concept map. Put nouns and phrases in bubbles. Connect related bubbles with arrows. Label the arrows with a description of the relationship between the connected bubbles. 